\title{
Annual scientific meeting 19 June 2017
}

\author{
LACK OF P66SHC IN THE CLL MOUSE MODEL \\ E $\mu$-TCL1 EXACERBATES NODAL \\ AND EXTRANODAL INFILTRATION \\ OF LEUKEMIC CELLS WHICH CAN UNDERGO \\ RICHTER'S TRANSFORMATION
}

\section{Patrussi, ${ }^{1}$ N. Capitani, ${ }^{1,2}$ C. Ulivieri, ${ }^{1}$ F. Cattaneo, ${ }^{1}$ N. Manganaro, ${ }^{1}$ M. Granai, ${ }^{3}$ S. Gobessi, ${ }^{4}$ D. Efremov, ${ }^{4}$ L. Leoncini, ${ }^{3}$ C.T. Baldari ${ }^{1}$}

${ }^{1}$ Department of Life Sciences, University of Siena; ${ }^{2}$ Department of Clinical and Experimental Medicine, University of Florence; ${ }^{3}$ Department of Human Biotechnologies, University of Siena; ${ }^{4}$ ICGEB, Trieste, Italy

\section{Purpose}

Chronic lymphocytic leukaemia (CLL) cells have a defective expression of the p66Shc adaptor which correlates with poor prognosis and disease severity [1]. The impairment in p66Shc expression alters the balance between homing and egress receptors [2,3], favouring the accumulation of leukemic cells in the pro-survival stromal microenvironment. Here we analysed the impact of p66Shc gene disruption on disease severity and progression.

Methods

We crossed E $\mu$-TCLl and p66Shc ${ }^{-/-}$to generate the new E $\mu$ -
TCL1/p66Shc ${ }^{-/-}$mouse strain. We analysed by flow cytometry blood samples from 140 mice of both strains to assess the percent of $\mathrm{CD}^{+} / \mathrm{CD} 19^{+}$tumoral cells. We stained tissues from both nodal and extranodal sites with haematoxylin/eosin to analyse tumoral infiltration and performed qRT-PCR of chemokine receptors in tumoral cells.

\section{Results}

We found that $\mathrm{E} \mu-\mathrm{TCL} 1 / \mathrm{p} 66 \mathrm{Shc}^{-/-}$mice develop an aggressive disease that has an earlier onset, a higher incidence and leads to an earlier death compared to E $\mu$-TCLl mice. A significant proportion of $\mathrm{E} \mu-\mathrm{TCL} 1 / \mathrm{p} 66 \mathrm{Shc}^{-/-}$mice displays substantial accumulation of leukemic cell not only at nodal but also at extranodal sites, which subverts organ architecture and in several instances develops into aggressive lymphomas, similar to Richter's transformation of CLL. We moreover found an upregulation in the expression of chemokine receptors whose ligands are known to be enriched at these sites.

\section{Discussion}

$\mathrm{E} \mu-\mathrm{TCL} 1 / \mathrm{p} 66 \mathrm{Shc}^{-/-}$develop a disease with an earlier onset and a worst prognosis. This is relatable to the increased expression of chemokine receptors which accounts for the infiltration of p66Shc $\mathrm{S}^{-/}$leukemic cells in nodal and extranodal sites.

\section{Conclusions}

Our results highlight p66Shc as a key regulator of CLL-like disease progression and severity in the TCL1 mouse model and identify E $\mu$-TCL1/p66Shc ${ }^{-/-}$mice as a new valuable model of aggressive CLL.

Key words: CLL; homing; p66Shc.

\section{HYDROXYTYROSOL REDUCES COLON CANCER GROWTH BY ENHANCING EPIDERMAL GROWTH FACTOR RECEPTOR DEGRADATION}

\section{E. Terzuoli E, L. Morbidelli, M. Ziche, S. Donnini}

Laboratory of Pharmacology of Angiogenesis and Pharmacogenetics, Department of Life Sciences, University of Siena, Italy

\section{Purpose}

It is nowadays well established how diet can influence tumour development, in particular of the gastrointestinal tract. Moreover, the protective effects of Mediterranean diet are universally recognized and the active phytochemicals have been identified, even if their mechanisms of action are not completely clarified.

\section{Methods}

In this work, we have studied the effects and mechanism of hydroxytyrosol (HT), a polyphenol present in extra-virgin olive oil, by investigating the regulation of epidermal growth factor receptor (EGFR) expression in colon tumour cells.
We demonstrated that HT significantly down-regulates EGFR expression in human colorectal adenocarcinoma cells HT-29, and in HT-29 inoculated mouse xenografts. HT accelerates EGFR degradation by reducing its half-life. Specifically, HT induces EGFR ubiquitination which is mediated by the phosphorylation at pY1045, the docking site for Cbl, thereby enabling receptor ubiquitination and degradation. Pre-treatment with either the lysosomal inhibitor chloroquine, or the proteasomal inhibitor MG132 blocks HT-induced EGFR down-regulation. In colon cancer cells, EGFR down-regulation by HT is associated with reduced cell proliferation. Tumour growth and EGFR expression levels are also decreased by oral HT treatment of HT-29 cell mouse xenograft.

\section{Conclusions}

We concluded that HT down-regulates EGFR expression via lysosomal and proteasomal degradation, activated by EGFR phosphorylation at pY1045 and increased Cbl activity. Cbl activation induces, as a consequence in turn, EGFR ubiquitination.

Our results reveal a new mechanism for HT's anti-tumour effects that may be important for colon tumour prevention and treatment.

Key words: tumour development; epidermal growth factor receptor; hydroxytyrosol. 


\section{Annual scientific meeting 19 June 2017}

\section{EFFECTS OF METABOLIC STRESS AND ISCHAEMIA ON URINARY BLADDER: GENDER DIFFERENCES}

\section{F. Pessina, ${ }^{1}$ L. Paulesu ${ }^{2}$ \\ ${ }^{1}$ Department of Molecular and Developmental Medicine and ${ }^{2}$ Department of Life Sciences, University of Siena, Italy}

The bladder wall becomes ischaemic when intravesical pressure rises above capillary pressure. This will occur routinely in bladders with outflow obstruction. In vivo ischemia in animal models results in bladder overactivity and the expression of apoptotic markers in intrinsic neurons in the bladder wall. In humans, bladders from patients with bladder instability show patchy denervation, suggesting that periodic ischemia and neuronal death may predispose to overactivity. Experiments in vitro in animal and human bladder show that the detrusor normally uses anaerobic as well as aerobic metabolism. Anoxic conditions result in an initial reduction in contractility, but significant contractile ability persists. Substrate removal causes a slow progressive fall in contractility as glycogen stores deplete. Removal of substrate and oxygen causes rapid loss of contractile ability and perma- nently damages intrinsic nerves, although the detrusor recovers well. Moreover, the addition of 2-deoxyglucose (2-DG), an inhibitor of glycolysis, during the anoxia and glucopenia, was shown to increase the intrinsic nerves damage and to extend the damage also to the smooth muscle. This damage was significantly more enhanced in male as compared to female rodent bladder. A significantly higher glycogen content was observed in female as compared to male bladders, which was inversely related with the duration of anoxia and glucopenia (A-G) exposure. The higher resistance of female bladder to A-G/reperfusion, could be partly ascribed to the higher glycogen content.

The neuroprotective effects of estrogens were demonstrated in in vitro studies and a great interest in soy isoflavones (genistein and daidzein) as alternative to the synthetic estrogen receptor modulators for therapeutic use has been pointed out. Estrogens given both in vivo (increased of Estrogen plasma levels were monitored) and in vitro, resulted to be neuroprotective in male rat bladder subjected to A-G/R damage, as well as genistein and daidzein. Moreover both phytoestrogens significantly decreased detrusor contractions in a concentration-dependent manner. For being either neuroprotective and myorelaxant, genistein and daidzein could be considered a good lead for new therapeutic agents to protect the urinary bladder from hyperactivity and nerve damage.

Key words: urinary bladder; phytoestrogen; anoxia/glucopenia.

\section{IL "SATOR" DISVELATO}

\section{G. Chiarini}

Department of Philology and Literary Criticism, University of Siena, Italy

Tutti sanno, a Siena, della piccola lapide col cosiddetto 'Quadrato magico', ovvero SATOR, incastonata nella fiancata Nord del Duomo di Siena. Oggi è possibile interpretare con metodo scientifico il significato dell'indovinello, le sue origini, la sua fortunata storia e diffusione, la sua complessità simbolica tutta legata all'astronomia antica e ai culti solari ('SATOR', il "Seminatore", è infatti il Sole esaltato nel suo percorso annuo). Ideato sotto Nerone nell'ambito delle iniziazioni mitraiche dell'esercito imperiale nella forma ROTAS/OPERA/TENET/AREPO/SATOR', il Quadrato continuò a prosperare anche nel nuovo universo cristianizzato in forma rovesciata, con 'ROTAS' all'ultimo posto e 'SATOR' al primo: onore attribuito a Cristo in qualità di "Nuovo Sole" $\mathrm{e}$ "[Buon] Seminatore".

Key words: astronomy; Sator; cathedral.

\section{CITIZEN SCIENTISTS: A NEW OPPORTUNITY TO SUPPORT ENVIRONMENTAL RESEARCH AND MANAGEMENT}

\section{Galgani, S. Loiselle, C. Rossi, A. Donati \\ Department of Biotechnologies, Chemistry and Pharmacy, University of Siena, Italy}

\section{Purpose}

Aquatic ecosystems are under increasing stress from climate change and environmental degradation. Diffuse pollution including and the release of new pollutants (e.g. microplastics, pharmaceuticals) into rivers, lakes and oceans across the globe represents is threatening the fundamental services that these ecosystems provide. To successfully control and mitigate this growing challenge and better understand its impact on the environment, novel methods are needed to connect local communities, local authorities and the scientific community. One potentially important approach to meeting this challenge is citizen science.

\section{Methods}

Using a consistent analysis and recording methodology, participants from local communities in Tuscany (and across the globe) are taking regular measurements to support the research of academic and institutional partners in their efforts to identify the sources and fate of freshwater pollutants. Local scale data combine with earth observation through online platforms provide high-resolution real-time information. These programmes have empowered communities, 


\section{Annual scientific meeting 19 June 2017}

strengthen research and improve evidenced-based management of our natural resources.

\section{Discussion}

Citizen observatories are expanding across the globe have been successful in supporting science and regulatory agencies. As part of a global network, information can be combined to help identify main drivers of ecosystem degradation and support innovative new approaches to the management of wastewater and waste flows. Participants in these programmes have positive impacts of their choices and actions with knock-on effects on local wastewater challenges. A significant increase $(90 \%)$ in participant's awareness and un- derstanding of local and global water issues shows clear benefits which result in a more engaged and empowered community.

\section{Conclusions}

Citizen observatories can create a critical mass of engaged and empowered community members as well as generating needed environmental data to support research and monitoring. The participating citizen scientists can make a significant contribution to support scientists to find innovative solutions to the managing our natural environment.

Key words: aquatic sciences; citizen science. 